\title{
Hydatid Cyst of the Psoas: A Rare Location
}

\author{
Pierlesky Elion Ossibi*, Issam Yazough, Saeed Abdul-Razak, Abdoul Aliou Zabeirou Oudou, \\ Karim Ibn Majdoub, Imane Toughrai, Said Ait Laalim, Khalid Mazaz
}

Visceral Surgery Department, Hassan II University Hospital, Fez, Morocco

Email: ${ }^{*}$ oselion@yahoo.fr

Received 5 February 2015; accepted 9 March 2015; published 11 March 2015

Copyright (C) 2015 by authors and Scientific Research Publishing Inc.

This work is licensed under the Creative Commons Attribution International License (CC BY).

http://creativecommons.org/licenses/by/4.0/

(c) (i) Open Access

\begin{abstract}
Hydatid cyst of the psoas is rare even in countries endemic to hydatidosis. We hereby report a case of hydatid cyst of the psoas in a 69 years old patient with a history of hypertension and had received left nephrectomy due to a renal abscess 2 years prior to his admission.
\end{abstract}

Keywords

Cyst, Hydatid, Psoas

\section{Introduction}

In countries endemic to hydatidosis, some rare locations of the disease have been described. Retroperitoneal location at the psoas muscle is exceptional, representing 3\% of muscle locations [1]. Clinical presentation remains non-specific. We report a case of hydatid cyst of the psoas in a 69 years old patient with a history of hypertension and had 2 years prior to his admission, a partial nephrectomy due to a left renal abscess.

\section{Case Presentation}

Patient, 69 years old male with hypertension placed under treatment who had received a partial nephrectomy 2 years prior to his admission, due to a left renal abscess with a current 6 month history of incipient swelling in left para lumbar fossa, gradually increasing in size and extending to the root of the thigh without other associated signs. On physical examination, patient was in good condition with a mass measuring 8 to $9 \mathrm{~cm}$ in diameter, tender, soft, extending from the left flank down to the root of the left thigh; without local inflammatory signs. Laboratory tests came back normal. Abdominal ultrasonography showed a large multilocular cystic lesion of the left flank extending to the root of the thigh. Abdominal CT revealed a multi locular collection left of the lateral abdominal wall taking up the psoas major muscle (Figure 1).

${ }^{*}$ Corresponding author.

How to cite this paper: Ossibi, P.E., Yazough, I., Abdul-Razak, S., Oudou, A.A.Z., Majdoub, K.I., Toughrai, I., Laalim, S.A. and Mazaz, K. (2015) Hydatid Cyst of the Psoas: A Rare Location. Surgical Science, 6, 123-125.

http://dx.doi.org/10.4236/ss.2015.63019 


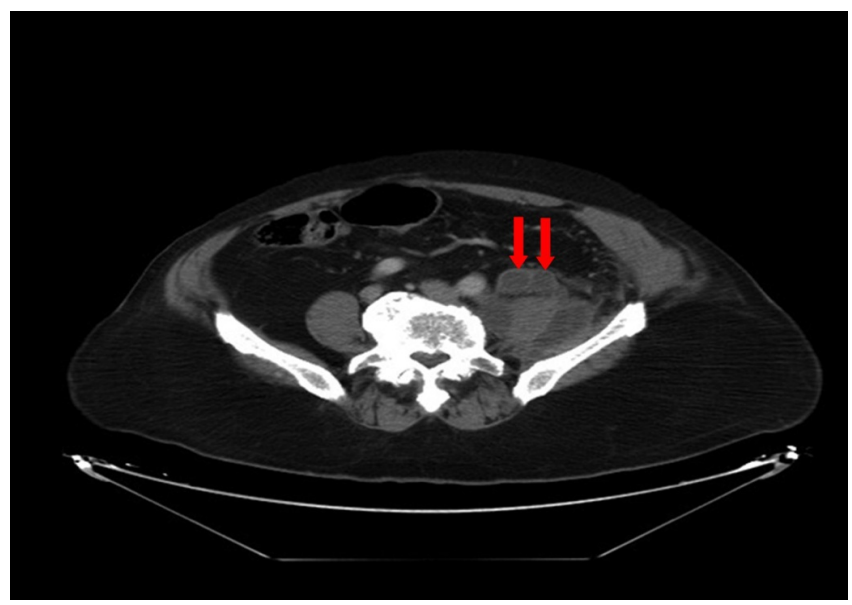

Figure 1. CT scan showing multi locularhydatid cyst (red arrow).

The patient was admitted to the operation block with per operative discovery of hydatid cyst which burst accidentally. Cyst was evacuated and patient was subsequently placed under oral Albendazol for 6 months with good response.

In the course of postoperative recovery, the following elements were checked: the surgical wound; liver enzymes and hydatidserology; as well as chest X-ray and abdominal ultrasonography which came back unremarkable with subsequent good clinical response.

Chest X-ray and abdominal ultrasonography were performed after surgery to diagnose other possible hydatid cyst locations and local recurrence. Surveillance ofhydatid serology was done every 2 months for up to a year after surgery to detect any possible recurrence while liver enzyme tests helped verify the safety of treatment (liver toxicity of albendazole).

\section{Discussion}

Hydatidosis is a cosmopolitan anthropozoonose [2]. The infection is mainly located in the liver and lungs. All other locations are possible but remain rare. The location at the psoas muscle is exceptional, representing $3 \%$ of muscle locations [1]. Hydatidosis is a disease transmitted by eggs of echinococusgranulosus. It is caused by ingesting food contaminated by animal excreta usually dogs which spread the parasite by feeding on worm infested meat. Uponeclosion off eggs in the digestive tract, the embryos may find their way into the liver. From there they may take up and develop in the lungs and other organs hence forming hydatid cysts.

The main symptoms are pain in the flanks with non-specific gastrointestinal symptoms such as nausea and vomiting. In most common cases, physical examination reveals a firm abdominal mass, rarely responsible for compression syndrome [3] [4]. Clinical and laboratory findings not providing sufficient specificity, it may be difficult to make a preoperative diagnosis [5].

Eosinophilia exists in $20 \%-50 \%$ of cases. This is particularly enhanced in case of cracking of the cyst. Seroimmunological reactions enhance the diagnosis. Indirect hemagglutination test is the most sensitive reaction with sensitivity up to $70 \%$.

Ultrasonography constitutes an innocuous first-line examination with an estimated $96 \%$ reliability. It follows Gharbi's classification [6]. Type I: Pure fluid collection; Type II: Collection with detached membrane; Type III: Multi vesicular collection with multiple septa and or daughter cysts (bee nest resemblance); Type IV: Solid tumor-like (hyperechoic with high internal echoes) lesion; Type V: Cyst with calcified wall. Although the use of high frequency ultrasonography can enhance study of cyst wall, in somedeep locations, such as the psoas, computerized tomography, CT is necessary as it allows easy diagnosis with a more accurate evaluation of the extent of disease. Morphological aspects encountered in CT scan are similar to those encountered in ultrasonography. MRI has a diagnostic value in cases where the cysts are atypical in ultrasound or even CT especially in tumorlike forms [7] [8].

Curative treatment of hydatid cyst of the psoas is surgical. Medical treatment with albendazole is gaining popularity. To some authors, it is reserved for inoperable patients or local recurrences in conjunction with sur- 
gery. In our case, patient was placed under oral Albendazole due to per operative rupture of the cyst [9]. The extra peritoneal approach remains the most appropriate [9]. Surgical excision should be done carefully in order not to open up the cyst during dissection.

\section{Conclusion}

Hydatid cyst of the psoas muscle is a rare location. It is a benign condition that must be considered in the presence of any lumbar or pelvic fluid mass especially in countries endemic to hydatidosis. The diagnosis is confirmed with ultrasound sometimes coupled with computed tomography.

\section{References}

[1] Ben Ayed, M., Kamoun, N., Makni, K. and Ben Romdhane, K. (1986) Hydatid Cyst: 281 Cases, of Which 86 Cases Had an Unusual Localization, Seen during a 10 Years Period (1972-1981). Tunisie Medicale, 64, 389-395.

[2] Horchani, A., Nouira, Y., Kbaier, I., Attyaoui, F. and Zribi, A.S. (2000) Hydatid Cyst of the Kidney. A Report of 147 Controlled Cases. European Urology, 38, 461-467. http://dx.doi.org/10.1159/000020325

[3] El Ouakdi, M., Ben Fadhel, S., Ayed, M. and Zmerli, S. (1988) Isolated Retroperitoneal Hydatid Cyst. A Propos of 4 Cases. Journal of Urology (Paris), 94, 445-448.

[4] Kaya, K., Gokce, G., Kaya, S., Kilicarslan, H., Ayan, S. and Gultekin, E.Y. (2006) Isolated Renal and Retroperitoneal Hydatid Cysts: A Report of 23 Cases. Tropical Doctor, 36, 243-246. http://dx.doi.org/10.1258/004947506778604977

[5] Gurdal, M., Kirecci, S., Yucebas, E. and Karaman, M.I. (2004) Primary Retroperitoneal Hydatid Cyst with Unusual Clinical Manifestation. Urology International, 73, 92-94. http://dx.doi.org/10.1159/000078813

[6] Gharbi, H.A., Hassine, W., Brauber, M.W. and Dupuch, K. (1981) Ultrasound Examination of the Hydatid Liver. Radiology, 139, 459-463. http://dx.doi.org/10.1148/radiology.139.2.7220891

[7] Angulo, J.C., Escribano, J., Diego, A. and Sanchez-Chabado, M. (1998) Isolated Retro Vesical and Extra Renal Retroperitoneal Hydatidosis Clinical Study of 10 Cases and Literature Review. Journal of Urology, 159, 76-82. http://dx.doi.org/10.1016/S0022-5347(01)64016-3

[8] Kiresi, D.A., Karabacakoglu, A., Odev, K. and Karakose, K. (2003) Uncommon Locations of Hydatid Cysts. Actaradiologica, 44, 622-636.

[9] Melis, M., Marongiu, L., Scintu, F., et al. (2002) Primary Hydatid Cysts of Psoas Muscle. ANZ Journal of Surgery, 72, 443-445. http://dx.doi.org/10.1046/j.1445-2197.2002.02420.x 